\title{
Inhibitory Effects of Paclitaxel Hirudin Complexes on the Growth and Proliferation of Human Coronary Artery Smooth Muscle Cells and Endothelial Cells in Vitro: An Exploration of a New Type of Complex Monomer for Stents Eluting Natural Herbs
}

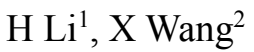

\begin{abstract}
Objective: To prove the effectiveness and feasibility of a paclitaxel hirudin complex and to provide experimental data on the prevention of restenosis, we investigated the effects of paclitaxel hirudin complexes on the growth of human coronary artery smooth muscle cells (HCASMCs) and endothelial cells (HCAECs) in vitro.

Methods: HCASMCs and HCAECs were co-incubated with different concentrations of hirudin. Cell viability was assessed using methylthiazoletetrazolium (MTT) assays to determine the optimal concentration range for inhibiting the growth of HCASMCs but not that of HCAECs. Then, cells were incubated with hirudin within the optimal concentration range combined with $1 \mu \mathrm{mol} / \mathrm{L}$ paclitaxel.

Results: Hirudin at $0.2-3.13 \mathrm{mg} / \mathrm{mL}$ significantly inhibited the growth of HCASMC $(\mathrm{p}<0.05)$ but not HCAEC ( $p>0.05$ ) compared to the control group. This range of hirudin complexed with $1 \mu \mathrm{mol} / \mathrm{L}$ paclitaxel noticeably inhibited the growth of HCASMC $(\mathrm{p}<0.05)$. Moreover, $1 \mu \mathrm{mol} / \mathrm{L}$ paclitaxel $+0.39 \mathrm{mg} / \mathrm{mL}$ hirudin noticeably decreased the inhibition ratio of the growth of HCAECs compared with the paclitaxel only group $(\mathrm{p}<0.05)$. The complex of $1 \mu \mathrm{mol} / \mathrm{L}$ paclitaxel plus 0.39 $\mathrm{mg} / \mathrm{mL}$ hirudin can maximize the inhibition of HCASMCs and minimum the inhibition of HCAECs.
\end{abstract}

Conclusions: The results of this study may provide reference data for the subsequent development of natural herb-eluting stents.

Keywords: Cardiovascular disease, drug-eluting stents, hirudin, inhibitory effects, paclitaxel

From: Institute for Cardiovascular Disease, Dongzhimen Hospital Affiliated to Beijing University of Chinese Medicine, Beijing 100700, China; Key Laboratory of Chinese Internal Medicine of Ministry of Education and Beijing, Dongzhimen Hospital Affiliated to Beijing University of Chinese Medicine, Beijing 100700, China.

Correspondence: Dr X Wang, Institute for Cardiovascular Disease, Dongzhimen Hospital Affiliated to Beijing University of Chinese Medicine, Beijing 100700, China. Email: wx657203@163.com 


\section{INTRODUCTION}

Atherosclerotic cardiovascular disease (ASCVD) is a major cause of death and seriously imperils human health (1). Percutaneous coronary intervention (PCI) is an important recent breakthrough in revascularizing occluded coronaries, and drug-eluting stents (DESs) have been widely used in the interventional treatment of ASCVD with significant anti-restenosis effect (2). However, the long-term outcome of DES treatment of ASCVD cannot be reliably judged. There is a $10 \%-20 \%$ DES restenosis rate after DES treatment (3). In partial DES treatments, the incidence of major adverse cardiac events was not decreased, and late stent thrombosis is a devastating complication that greatly limits the long-term curative effect of $\operatorname{DESs}(4,5)$.

Restenosis caused by over-healing after percutaneous coronary revascularization is the major obstacle in the development of PCI (6). Randomized clinical and experimental studies have confirmed that exaggerated neointimal thickening and muscle cell transfer induced by vascular injury caused by the intervention process are the main pathological characteristics of restenosis after PCI (7-9). Compared with bare-metal stents (BMSs), DESs reduce the clinical restenosis rate significantly by inhibiting intimal neoproliferation (10). However, this effect is associated with delayed or deficient re-endothelialization, and the neointimal coverage is closely related to the intrastent restenosis and thrombosis (11). The chemical ingredients loaded on the drug-eluting stents are less selective. Chemical ingredients may not only suppress the proliferation of vascular smooth muscle cells (VSMCs) but also inhibit re-endothelialization of the wound site, causing delayed healing and in-stent thrombosis (12). Therefore, seeking a way to minimize the incidence of in-stent restenosis and to avoid late thrombotic complications is a subject of interest.

Natural herbs are a newer research focus in drug-eluting stent methods. Several herbal active ingredients, such as hirudin, ligustrazine, emodin, allicin, celastrol and salvia 
miltiorrhiza, loaded on drug-eluting stents have good biocompatibility as well as anti-proliferative and anti-thrombotic effects (13). Among these effective monomers of natural herbs, hirudin, with a unique antithrombotic effect, attracted our attention.

An extract of leech saliva, hirudin is a direct thrombin inhibitor, unlike heparin. Its role in the inhibition or inactivation of thrombin is not dependent on antithrombin III, heparin cofactor II, protein $\mathrm{C}$ or tissue factor pathway inhibitor. Hirudin is not inactivated by platelet combination and can inhibit thrombin-induced platelet aggregation. Hirudin has good anti-coagulant and antithrombotic effects $(14,15)$. Hirudin could effectively inhibit the hyperplasia of smooth muscle cells (SMCs) in the arterial intima and significantly reduce the intima thickness and the incidence of restenosis after transluminal angioplasty (TA).

Hirudin may also play a role in the prevention of restenosis after TA (16). Hirudin inhibits tritiated thymidine $(3 \mathrm{H}-\mathrm{TdR})$ incorporation and the proliferation and migration of cultured rabbit aortic SMCs in a concentration-dependent manner (17). Hirudin can be used to prevent restenosis after PCI and has promising prospects in the future (18-20). However, because the components of herbs are complex, the exact effects of selected natural herbal monomers on anti-proliferation and protection against vascular endothelial function are unclear. The effects of a single drug (i.e., hirudin) on the growth of human vascular cells are seldom reported. Most related experimental models are animal cells, and intervention studies of natural herbs on human coronary arteries are rare.

A new biodegradable stent coated with hirudin and the prostacyclin analogue iloprost can inhibit neointima formation and reduce the risk of clots after experimental coronary artery stenting (21-23). Two or more compounds may reduce in-stent restenosis and prevent thrombosis more effectively, and the use of the combination of hirudin and other anti-proliferative drugs in preparing drug-coated stents is feasible. We proposed a strategy for amplifying the advantages of hirudin and enhancing efficiency by combining hirudin with a 
natural herb monomer that had a good anti-proliferative effect on SMCs but could not protect endothelial cells.

On the basis of these hypotheses, combined with the latest research progress, we chose paclitaxel and hirudin to prepare the compound. The purpose of this study was to obtain the appropriate ratio of paclitaxel to hirudin to provide experimental data and new hypotheses for the research and development of natural herb-eluting stents.

\section{MATERIALS AND METHODS}

\section{Materials and reagents}

Human coronary artery smooth muscle cells (HCASMCs) and endothelial cells (HCAECs), HCASMC and HCAEC media, Trypsin EDTA, Trypsin Neutralizing Solution, and FrostaLife Cryopreservation were purchased from Lifeline Corporation, Carlsbad, CA, USA. Phosphate-buffered saline (PBS), methyl thiazolyl tetrazolium (MTT), and dimethylsulfoxide (DMSO) were purchased from Beijing Solarbio Science \& Technology Co., Ltd., Beijing, China. The paclitaxel storage solution was obtained from Nanjing KeyGEN Biotech. Co., Ltd., Nanjing, China. Scientific grade natural lyophilizing hirudin powder (500 AT-U/g) was purchased from Wuhan Shengtianyu Biological Science and Technology Co., Ltd., China.

\section{HCASMC and HCAEC cultures}

Frozen aliquots of cells were obtained from liquid nitrogen storage and immediately thawed at $37^{\circ} \mathrm{C}$. The cells were injected into a $25-\mathrm{cm}^{3}$ culture bottle and cultivated in an incubator containing $95 \% \mathrm{O}_{2}$ and $5 \% \mathrm{CO}_{2}$ at $37{ }^{\circ} \mathrm{C}$. The medium was replaced every two days. The cells were passaged every 3 to 4 days. The cells were used in the following experiments at passage 4 or 5 .

\section{Determination of the optimal concentration range of hirudin}




\section{Grouping}

The cells were divided into a zero-adjustment group (one well without cells), a control group (cells were cultured normally without stimulation in five wells), and the drug intervention groups at different doses $(0.025,0.05,0.1,0.2,0.39,0.78,1.56,3.13$, and 6.25 $\mathrm{mg} / \mathrm{mL}$ ) (24). Six replicates were performed for each experimental group.

\section{Cell inoculation}

HCASMCs and HCAECs at 70\%-80\% confluency were digested into single-cell suspensions, and the cell density was adjusted to $8 \times 10^{4} / \mathrm{mL}$. The cells were subsequently seeded onto 96-well plates. Cell suspensions $(100 \mu \mathrm{L})$ were added to each well, except that only culture medium was placed in the zero-adjustment well. The medium was replaced daily. Subsequently, $0.05 \mathrm{~mL}$ of the cell suspension was mixed with $0.05 \mathrm{~mL}$ of trypan blue for staining. The cell viability by this method was $95 \%$.

\section{Drug stimulation}

The cells were washed twice with PBS. Then, $100 \mu \mathrm{L}$ of basic culture medium was added to the zero-adjustment well and control group wells, and $100 \mu \mathrm{L}$ of hirudin at different concentrations was added to the drug intervention groups. The cells were cultivated in an incubator containing $95 \% \mathrm{O}_{2}$ and $5 \% \mathrm{CO}_{2}$ at $37{ }^{\circ} \mathrm{C}$ for $48 \mathrm{~h}$.

\section{Evaluation of cell viability}

The MTT method was used to assess the cell viability according to the literature (25). After co-incubation for $48 \mathrm{~h}, 20 \mu \mathrm{L}$ of MTT solution was added to each well. Subsequently, the supernatant was discarded, and $150 \mu \mathrm{L}$ DMSO was added. The cells were gently oscillated for $10 \mathrm{~min}$. Cell viability was read at $492 \mathrm{~nm}$ using an enzyme-labeled instrument. The inhibition rate of each group was calculated based on the following formula:

Inhibition rate $(\mathrm{IR})=\left(1-\mathrm{A}_{492} \mathrm{~nm}\right.$ of experimental group/ $\mathrm{A}_{492 \mathrm{~nm}}$ of control group $) \times 100 \%$. Based on the inhibition rates of the groups, an optimal concentration range of hirudin was 
determined.

\section{Determination of the inhibitory effects of different ratios of the complexes}

\section{Grouping}

To prepare the paclitaxel+hirudin complexes, $1 \mu \mathrm{mol} / \mathrm{L}$ paclitaxel (26) was added to various hirudin solutions within the optimal concentration range. The cells were co-incubated with different paclitaxel+hirudin complexes in 96-well culture plates, and six replicates were arranged in a separate well for each dose group. The first 5 wells contained culture medium as the control group, and the remaining well was the zero-adjustment group. The second 6 wells contained paclitaxel only and are identified as the paclitaxel only group.

\section{Cell inoculation and drug stimulation}

Cell inoculation was performed according to the method described above. The cells were washed twice with PBS every day, and $100 \mu \mathrm{L}$ of basic culture medium was added to the zero-adjustment well and control group wells. Then, $100 \mu \mathrm{L}$ of paclitaxel $(1 \mu \mathrm{mol} / \mathrm{L})$ was added to the paclitaxel only group. First, $50 \mu \mathrm{L}$ of paclitaxel $(2 \mu \mathrm{mol} / \mathrm{L})$ was added to the drug intervention groups with different doses. Then, $50 \mu \mathrm{L}$ of hirudin with the double dose was added. The cells were then cultivated in an incubator containing $95 \% \mathrm{O}_{2}$ and $5 \% \mathrm{CO}_{2}$ at $37^{\circ} \mathrm{C}$ for $48 \mathrm{~h}$.

\section{Evaluation of cell viability}

The change in cell growth activity was detected using the MTT colorimetric method to observe the state of normally cultured HCASMCs and HCAECs that were treated with paclitaxel+hirudin complexes at different concentrations. The appropriate ratio of paclitaxel to hirudin to maximize the inhibition of HCASMCs while minimizing the inhibition of HCAECs was then determined.

\section{Statistical analyses}

The data are expressed as the means \pm SEM. The statistical evaluation was performed using 
SPSS17.0 software. The statistical comparisons were performed using a one-way analysis of variance (ANOVA). Dunn's method was used to discriminate the differences among different groups. $P<0.05$ was considered to be statistically significant.

\section{RESULTS}

\section{Cell culture in vitro}

Under the inverted microscope, newly recovered HCASMCs and HCAECs were small, round and floating in the medium in a non-adherent state. Most of the cells were separated from each other or agglomerated. After a 6-h cultivation, the majority of the cells gradually attached to the bottom; all of the cells were completely attached to the bottom after $24 \mathrm{~h}$. The shape of the attached HCASMCs gradually changed into a spindle, with good stretching and diaphaneity. In 3 days, the cells entered the logarithmic growth phase, with a dense bundle arrangement and overlapping (Figures $1 \mathrm{~A}$ and B). The attached HCAECs were transformed into a confluent single layer and then entered the logarithmic growth phase in 4 days. The cell body was plump and transparent with a rhombic or polygonal shape, in a "slabstone" arrangement (Figures $1 \mathrm{C}$ and $\mathrm{D})$.

\section{Optimal concentration range of hirudin}

On the growth of HCASMCS

Under the inverted microscope, newly inoculated HCASMC were small, round, and floating in the medium. In $2 \mathrm{~h}$, the shape of the attached cells gradually changed into a spindle shape. In $48 \mathrm{~h}$, the cells entered the logarithmic growth phase with a dense bundle arrangement and overlapped each other. There was no obvious change in cell morphology or quantity after 


\section{Effects of Hirudin Complexes on HCASMCs and HCAECs}

48-h stimulation with a low dose of hirudin $(0.025-0.1 \mathrm{mg} / \mathrm{mL})$. After a $24-\mathrm{h}$ stimulation with medium and high doses of hirudin $(0.39-6.25 \mathrm{mg} / \mathrm{mL})$, the cell morphology was slightly different. After $48 \mathrm{~h}$, the quantity of cells was reduced, and the arrangement became loose. At $48 \mathrm{~h}$ after stimulation, compared to the control group, low-dose hirudin $(0.025-0.1 \mathrm{mg} / \mathrm{mL})$ did not noticeably inhibit the growth of HCASMCs $(P>0.05)$. The medium and high doses of hirudin $(0.2-6.25 \mathrm{mg} / \mathrm{mL})$ obviously inhibited the growth of HCASMCs $(P<0.05)$, and the inhibitory rate increased with the increase in the hirudin concentration (Table 1, Figure 2).

\section{On the growth of HCAECs}

Under the inverted microscope, newly inoculated HCAECs were round and floating in the medium. Most of the cells were separated from each other or agglomerated. At $2 \mathrm{~h}$, the majority of cells gradually attached to the bottom, and all of the cells were completely attached to the bottom at $24 \mathrm{~h}$ after stimulation. The "slabstone" arrangement appeared within $48 \mathrm{~h}$. There were no obvious changes in cell morphology or quantity. The cells formed a confluent single layer after 48-h stimulation with low and medium doses of hirudin $(0.025-3.13 \mathrm{mg} / \mathrm{mL})$. After 48 -h stimulation with a high dose of hirudin $(6.25 \mathrm{mg} / \mathrm{mL})$, the quantity of cells was reduced, and partially attached cells dropped from the well walls.

At $48 \mathrm{~h}$ after stimulation, compared to the control group, the $0.025-3.13 \mathrm{mg} / \mathrm{mL}$ hirudin treatments did not noticeably inhibit the growth of HCAECs $(P>0.05)$. Hirudin at $6.25 \mathrm{mg} / \mathrm{mL}$ obviously inhibited the growth of HCAECs $(P<0.05)$, and $0.05-0.2 \mathrm{mg} / \mathrm{mL}$ of hirudin increased the growth of HCAECs (Table 2, Figure 2). Based on these results, we chose the low dose of hirudin $(0.2-3.13 \mathrm{mg} / \mathrm{mL})$ as the optimal concentration range that could inhibit the growth of HCASMCs and increase the growth of HCAECs.

\section{Inhibitory effects of the complexes}

\section{On HCASMCs}

Under the inverted microscope, HCASMCs in the logarithmic growth stage overlapped and 
were in a dense bundle arrangement. After drug stimulation for $48 \mathrm{~h}$, both paclitaxel only and various doses of paclitaxel+hirudin complexes decreased the number of cells and loosened the cell arrangement. The degree of change was positively associated with the hirudin concentration.

Compared to the control group, paclitaxel only and various doses of paclitaxel+hirudin complexes noticeably inhibited the growth of HCASMCs $(P<0.05)$. Compared with paclitaxel only, various doses of paclitaxel+hirudin complexes increased the growth inhibition of HCASMCs $(P<0.05)$. The complexes had higher inhibition rates than paclitaxel only $(P<0.05)$, but the inhibitory rate did not increase with the increase in the hirudin concentration (Table 3, Figure 3).

\section{On HCAECs}

Under the inverted microscope, HCAECs in the logarithmic growth were arranged in a "slabstone" pattern. After drug stimulation for $48 \mathrm{~h}$, both paclitaxel only and various doses of paclitaxel+hirudin complexes reduced the quantity of cells and loosened the cell arrangement. Partial cells were observed floating in the medium and could not be attached to the bottoms of wells.

Compared to the control group, paclitaxel only and various doses of the paclitaxel+hirudin complexes noticeably inhibited the growth of HCASMCs $(P<0.05)$. Compared with paclitaxel only, paclitaxel $+0.39 \mathrm{mg} / \mathrm{mL}$ hirudin and paclitaxel $+0.78 \mathrm{mg} / \mathrm{mL}$ hirudin significantly decreased the growth inhibition HCAECs $(P<0.05)$, but the inhibitory rate did not increase with the increase in the concentration of the complexes (Table 4, Figure 3).

\section{DISCUSSION}


The restenosis rate of $10 \%-20 \%$ after DES treatment of ASCVD remains a challenge for clinicians (3). Proliferation and migration of VSMCs and delayed endothelialization are believed to be the main pathological causes of in-stent restenosis (27). The results of this study revealed that paclitaxel hirudin complexes had a higher inhibition rate than the paclitaxel only treatment, suggesting that natural herbs have the capacity to enhance pharmacological effects. Moreover, the appropriate ratio of the paclitaxel+hirudin complex (1 $\mu \mathrm{mol} / \mathrm{L}$ paclitaxel $+0.39 \mathrm{mg} / \mathrm{mL}$ hirudin) could decrease the growth inhibition of HCAECs and maximize the inhibition of HCASMCs, suggesting that natural herbs have the capacity to reduce the poison effects. Thus, the compatibility of paclitaxel and hirudin could effectively reduce the negative effects caused by the single drug. This study provides experimental data for the prevention of restenosis after DES treatment and proposes a new idea for the research and development of drug-eluting stents.

DES intervenes in the pathological process of restenosis to target lesions locally, and its good effects have been shown in many animal models and clinical studies $(28,29)$. Pharmacological inhibitors of neointimal hyperplasia, such as paclitaxel, are commercially available agents. Paclitaxel is a derivatized diterpenoid that exerts an antineoplastic effect by interfering with cell microtubule function. Paclitaxel alters the dynamic equilibrium among microtubules and $\alpha$ - and $\beta$-tubulin by favoring the formation of abnormally stable microtubules, which leads to the inhibition of cell division and migration, intracellular signaling, and protein secretion, which rely on the rapid and efficient depolymerization of microtubules (30-32). However, microtubules, the major components of cytoskeleton proteins, also usually are found in HCAECs. Although the paclitaxel stent can inhibit the migration and proliferation of VSMCs and can contribute to neointimal hyperplasia, it can also delay the re-endothelialization of the intima, with the potential risk of late thrombosis (33-36). The results of the aspirin-induced platelet effect test on paclitaxel-eluting stents showed that the 
occurrence of sub-acute thrombosis in the high-dose paclitaxel group $\left(3.1 \mu \mathrm{g} / \mathrm{m}^{2}\right)$ was $2 \%$, which was higher than that in the low-dose group $\left(1.3 \mu \mathrm{g} / \mathrm{m}^{2}\right)$ (37). Therefore, it is important to select the best dose and proportion of paclitaxel for SMCs and epithelial cells. However, the combination application of paclitaxel and other anti-proliferation drugs, especially natural herbs, in preparing drug-coated stents has not been reported. In this study, $1 \mu \mathrm{mol} / \mathrm{L}$ paclitaxel was added to the optimal concentration range of hirudin to prepare different ratios of paclitaxel+hirudin complexes. We investigated the inhibitory effects of different ratios of paclitaxel+hirudin complexes on the growth of HCASMCs and HCAECs cultivated in vitro, highlighted the efficiency of paclitaxel+hirudin complexes as a new therapeutic strategy and identified $1 \mu \mathrm{mol} / \mathrm{L}$ paclitaxel plus $0.39 \mathrm{mg} / \mathrm{mL}$ hirudin as our final ratio of paclitaxel+hirudin complexes for the follow-up experiment.

Our study indicated that paclitaxel continuously inhibited SMC proliferation during the observation period and that the intact endothelium was essential in the prevention of SMC proliferation. At the same time, we successfully combined paclitaxel with hirudin to amplify the advantages of hirudin and achieved our efficiency-enhancing purpose. These results implied that we should not consider the "anti-tumor" approach only in restenosis prevention; optimal revascularization results would be achieved if the endothelial regeneration were simultaneously accelerated.

This study has some limitations. First, it was an in vitro study; additional studies in vivo are required. Second, the targets of the specific mechanism of paclitaxel+hirudin complexes are unclear and require further clarification.

The optimal composition of the paclitaxel+hirudin complex is $1 \mu \mathrm{mol} / \mathrm{L}$ paclitaxel plus $0.39 \mathrm{mg} / \mathrm{mL}$ hirudin, which can maximize HCASMC inhibition and minimize HCAEC inhibition. This preliminary study confirmed that reasonable compatibility of natural herbs can effectively reduce the negative effects caused by the single drug. By combining the 
advantages of natural herbs (i.e., multiple targets and wide efficacy) with advanced modern technologies, we demonstrated the efficacy and feasibility of paclitaxel+hirudin complexes. Meanwhile, the results of this study may lead the research and development of natural herb-eluting stents in new directions.

\section{ACKNOWLEDGMENTS}

This work was supported by the National Natural Science Foundation (Grant No. 81273913).

\section{AUTHORS' NOTE}

The authors declare no conflict of interests. 


\section{REFERENCES}

1. Van Camp G. Cardiovascular disease prevention. Acta Clin. Belg 2014; 69: 407-11.

2. Papafaklis MI, Chatzizisis YS, Naka KK, Giannoglou GD, Michalis LK. Drug-eluting stent restenosis: effect of drug type, release kinetics, hemodynamics an d coating strategy. Pharmacol Ther 2012; 134: 43-53.

3. Ko YG, Kim JS, Kim BK, Choi D, Hong MK, Jeon DW et al. Efficacy of drug-eluting stents for treating in-stent restenosis of drug-eluting stents (from the Korean DES ISR multicenter registry study [KISS]). Am J Cardiol 2012; 109: 607-13.

4. Charpentier E, Barna A, Guillevin L, Juliard JM. Fully bioresorbable drug-eluting coronary scaffolds: A review. Arch Cardiovasc Dis 2015; 2015: 1875-2136.

5. Mitsutake Y, Ueno T, Ikeno F, Yokoyama S, Sasaki KI, Nakayoshi T et al. Serial changes of coronary endothelial function and arterial healing after paclitaxel-eluting stent implantation. Cardiovasc Interv Ther 2016; 31: 21-8.

6. Li S, Zhang S, Li N, Li Z, Yu B, Tian Y. Arterial smooth muscle injury causes blood tissue factor elevation predicting restenosis after pci. Scand Cardiovasc J 2012, 46, 87-92

7. Paul A, Shao W, Shum-Tim D, Prakash S. The attenuation of restenosis following arterial gene transfer using carbon nanotube coated stent incorporating TAT/DNA (Ang1+Vegf) nanoparticles. Biomaterials 2012; 33: 7655-64.

8. $\quad \mathrm{Hu} \mathrm{X}$, Wang Z, Wu H, Jiang W, Hu R. Ras ssDNA aptamer inhibits vascular smooth muscle cell proliferation and migration through MAPK and PI3K pathways Int J Mol Med 2015; 35: 1355-61.

9. Austin KM, Nguyen N, Javid G, Covic L, Kuliopulos A. Noncanonical matrix metalloprotease-1-protease-activated receptor-1 signaling triggers vascular smooth 
Effects of Hirudin Complexes on HCASMCs and HCAECs

muscle cell dedifferentiation and arterial stenosis. J Biol Chem 2013; 288: 23105-15.

10. Yin RX, Yang DZ, Wu JZ. Nanoparticle Drug- and Gene-eluting Stents for the Prevention and Treatment of Coronary Restenosis. Theranostics 2014; 4: 175-200.

11. Murase S, Suzuki Y, Yamaguchi T, Matsuda O, Murata A, Ito T. The relationship between re-endothelialization and endothelial function after DES implantation: Comparison between paclitaxcel eluting stent and zotarolims eluting stent. Catheter Cardiovasc Interv 2014; 83: 412-7.

12. Nasuno T, Tokura M, Kageyama M, Toyoda S, Sakuma M, Komatsu T et al. The wound healing response after implantation of a drug-eluting stent is impaired persistently in the long term. Heart Vessels. 2015; 2015: 1-5.

13. van Beusekom HM, Ertaş G, Sorop O, Serruys PW, van der Giessen WJ. The genous (TM) endothelial progenitor cell capture stent accelerates stent re-endothelialization but does not affect intimal hyperplasia in porcine coronary arteries. Catheter Cardiovasc Interv 2012; 79: 231-42.

14. Pan XY, Peng L, Han ZQ, Yin GQ, Song YK, Huang J. Hirudin promotes angiogenesis by modulating the cross-talk between p38 MAPK and ERK in rat ischemic skin flap tissue. Tissue Cell 2015; 47: 301-10.

15. Gu X, Zhang X, Lu G, Li Y, Li X, Huang H et al. Effects of thrombin and thrombin receptor activation on cardiac function after acute myocardial infarction. Am J Transl Res 2015; 7: 654-69.

16. Huang Y, Zhang Y, Zhao B, Xu Q, Zhou X, Song H et al. Structural basis of RGD-hirudin binding to thrombin: Tyr3 and five C-terminal residues are crucial for inhibiting thrombin activity. BMC Struct Biol 2014; 14: 26.

17. Sun D, Hao Y, Yang G, Wang J. Hemocompatibility and cytocompatibility of the 
hirudin-modified silk fibroin. J Biomed Mater Res B Appl Biomater 2015; 103: $556-62$.

18. Hsieh YS, Wijeyewickrema LC, Wilkinson BL, Pike RN, Payne RJ. Total synthesis of homogeneous variants of hirudin P6: a post-translationally modified anti-thrombotic leech-derived protein. Angew Chem Int Ed Engl 2014; 53: 3947-51.

19. Roddick LA, Bhakta V, Sheffield WP. Fusion of the C-terminal triskaidecapeptide of hirudin variant 3 to alpha1-proteinase inhibitor M358R increases the serpin-mediated rate of thrombin inhibition. BMC Biochem 2013; 14: 31 .

20. $\mathrm{Xu} \mathrm{Y,} \mathrm{Wu} \mathrm{W,} \mathrm{Wang} \mathrm{L,} \mathrm{Chintala} \mathrm{M,} \mathrm{Plump} \mathrm{AS,} \mathrm{Ogletree} \mathrm{ML} \mathrm{et} \mathrm{al.} \mathrm{Differential}$ profiles of thrombin inhibitors (heparin, hirudin, bivalirudin, and dabigatran) in the thrombin generation assay and thromboelastography in vitro. Blood Coagul. Fibrinolysis 2013; 24: 332-8.

21. Kassis HM, Minsinger KD, McCullough PA, Block CA, Sidhu MS, Brown JR. A review of the use of iloprost, a synthetic prostacyclin, in the prevention of radiocontrast nephropathy in patients undergoing coronary angiography and intervention. Clin Cardiol 2015; 38: 492-8.

22. Koppara T, Cheng Q, Yahagi K, Mori H, Sanchez OD, Feygin J et al. Thrombogenicity and early vascular healing response in metallic biodegradable polymer-based and fully bioabsorbable drug-eluting stents. Circ Cardiovasc Interv 2015; 8: e002427.

23. Lv J, Wu Y, Zhang X, Jing T, Zhang L, Tong S et al. Comparison of the safety and efficacy of biodegradable polymer drug-eluting stents versus durable polymer drug-eluting stents: a meta-analysis. Eur J Med Res 2015; 20: 21.

24. Ren XX. Effects of paclitaxel hirudin complex on the growth of vascular endothelial cells and smooth muscle cells of rabbits, dissertation, Shanxi Medical University, 
Effects of Hirudin Complexes on HCASMCs and HCAECs

Taiyuan, China, 2011.

25. Situ ZQ, Wu JZ. Cell culture. Beijing World Publishing Corporation. 1996; 186-8.

26. Wang X, Zhao HB, Hu DY. Effects of paclitaxel hirudin complex on proliferation and migration of vascular smooth muscle cells and endothelial cells of rabbits, Chin. J Evid Based Cardiovasc Med 2009; 1: 99-103.

27. Zhang SS, Wang W, Zhao CQ, Xie MJ, Li WY, Yang XL et al. Inhibitory effects of roscovitine on proliferation and migration of vascular smooth muscle cells in vitro. J Huazhong Univ Sci Technolog Med Sci 2014; 34: 791-5.

28. $\mathrm{Hu} \mathrm{T}$, Yang J, Cui K, Rao Q, Yin T, Tan L et al. Controlled Slow-Release Drug-Eluting Stents for the Prevention of Coronary Restenosis: Recent Progress and Future Prospects. ACS Appl Mater Interfaces 2015; 7: 11695-712.

29. Ota H, Mahmoudi M, Torguson R, Satler LF, Suddath WO et al. Safety and efficacy of everolimus-eluting stents for bare-metal in-stent restenosis. Cardiovasc Revasc Med 2015; 16: 151-5.

30. Gongora CA, Shibuya M, Wessler JD, McGregor J, Tellez A, Cheng Y et al. Impact of Paclitaxel Dose on Tissue Pharmacokinetics and Vascular Healing: A Comparative Drug-Coated Balloon Study in the Familial Hypercholesterolemic Swine Model of Superficial Femoral In-Stent Restenosis. JACC Cardiovasc Interv 2015; 8: 1115-23.

31. Habara S, Kadota K, Shimada T, Ohya M, Amano H, Izawa Y et al. Late restenosis after paclitaxel-coated balloon angioplasty occurs in patients with drug-eluting stent restenosis. J Am Coll Cardiol 2015; 66: 14-22.

32. Habara S, Kadota K, Kanazawa T, Ichinohe $\mathrm{T}$, Kubo S, Hyodo $\mathrm{Y}$ et al. Paclitaxel-coated balloon catheter compared with drug-eluting stent for drug-eluting stent restenosis in routine clinical practice. EuroIntervention 2016; 11: 1098-105.

33. Kubo S, Kadota K, Otsuru S, Hasegawa D, Habara S, Tada $\mathrm{T}$ et al. 
Li and Wang

Everolimus-eluting stent implantation versus repeat paclitaxel-coated balloon angioplasty for recurrent in-stent restenosis lesion caused paclitaxel-coated balloon failure. EuroIntervention 2015; 10: e1-8.

34. Jim MH, Yiu KH. Combined drug-eluting stent and supplementary paclitaxel-eluting balloon application at side branch ostium for in-stent restenotic true bifurcation lesion. Int J Cardiol 2015; 181: 149-51.

35. Vos NS, Dirksen MT, Vink MA, van Nooijen FC, Amoroso G, Herrman JP et al. Safety and feasibility of a PAclitaxel-eluting balloon angioplasty in Primary Percutaneous coronary intervention in Amsterdam (PAPPA): one-year clinical outcome of a pilot study. EuroIntervention 2014; 10: 584-90.

36. Lee $\mathrm{CH}$, Yu CY, Chang SH, Hung KC, Liu SJ, Wang CJ et al. Promoting endothelial recovery and reducing neointimal hyperplasia using sequential-like release of acetylsalicylic acid and paclitaxel-loaded biodegradable stents. Int $\mathrm{J}$ Nanomedicine 2014; 9: 4117-33.

37. Jing L, Peng X, Xie MJ, Yu ZY, Wang W. Different responses of cell cycle between rat vascular smooth muscle cells and vascular endothelial cells to paclitaxel. J Huazhong Univ Sci Technolog Med Sci 2014; 34: 370-5. 
Effects of Hirudin Complexes on HCASMCs and HCAECs

Table 1: Inhibitory effects of hirudin on the growth and proliferation of HCASMCs $48 \mathrm{~h}$ after stimulation

\begin{tabular}{llll}
\hline Group no. & $\begin{array}{l}\text { Hirudin concentration } \\
(\mathbf{m g} / \mathbf{m L} \mathbf{)}\end{array}$ & $\mathbf{A 4 9 2} \mathbf{~ n m}(\mathbf{X} \pm \mathbf{S})$ & $\begin{array}{l}\text { Inhibition } \\
\mathbf{( \% )}\end{array}$ \\
\hline 1 & 0 & $0.605 \pm 0.080$ & 0 \\
2 & 0.025 & $0.552 \pm 0.025$ & 8.76 \\
3 & 0.05 & $0.539 \pm 0.018$ & 10.91 \\
4 & 0.1 & $0.551 \pm 0.061$ & 8.93 \\
5 & 0.2 & $0.516 \pm 0.069^{*}$ & 14.71 \\
6 & 0.39 & $0.471 \pm 0.101^{*}$ & 22.15 \\
7 & 0.78 & $0.416 \pm 0.044^{*}$ & 31.24 \\
8 & 1.56 & $0.332 \pm 0.049^{*}$ & 45.12 \\
9 & 3.13 & $0.271 \pm 0.056^{*}$ & 55.21 \\
10 & 6.25 & $0.134 \pm 0.049^{*}$ & 77.85 \\
\hline
\end{tabular}

${ }^{*} P<0.05$ vs. the control.

Table 2: Inhibitory effects of hirudin on the growth and proliferation of HCAECs $48 \mathrm{~h}$ after stimulation

\begin{tabular}{llll}
\hline Group no. & $\begin{array}{l}\text { Hirudin } \\
\text { concentration } \\
(\mathbf{m g} / \mathbf{m L})\end{array}$ & $\mathbf{A} \mathbf{4 9 2} \mathbf{~ n m} \mathbf{( X \pm S )}$ & Inhibition rate (\%) \\
\hline 1 & 0 & $0.280 \pm 0.036$ & 0 \\
2 & 0.025 & $0.262 \pm 0.067$ & 6.43 \\
3 & 0.05 & $0.291 \pm 0.067$ & -3.93 \\
4 & 0.1 & $0.290 \pm 0.085$ & -3.57 \\
5 & 0.2 & $0.285 \pm 0.049$ & -1.79 \\
6 & 0.39 & $0.273 \pm 0.062$ & 2.5 \\
7 & 0.78 & $0.259 \pm 0.046$ & 7.5 \\
8 & 1.56 & $0.223 \pm 0.055$ & 20.4 \\
9 & 3.13 & $0.222 \pm 0.044$ & 20.7 \\
10 & 6.25 & $0.155 \pm 0.050^{\#}$ & 44.6 \\
\hline
\end{tabular}

${ }^{*} P<0.05$ vs. the control. 
Table 3: Inhibitory effects of paclitaxel+hirudin complexes on HCASMCs (48 h)

\begin{tabular}{llll}
\hline Group no. & $\begin{array}{l}\mathbf{1} \\
\text { paclitaxel+different } \\
\text { doses of hirudin } \\
(\mathbf{m g} / \mathbf{m L})\end{array}$ & $\mathbf{A 4 9 2} \mathbf{~ n m}(\mathbf{X} \pm \mathbf{S})$ & $\begin{array}{l}\text { Inhol/L } \\
\text { rate (\%) }\end{array}$ \\
\hline 1 & 0 & & 0 \\
2 & Paclitaxel only & $0.769 \pm 0.078^{\#}$ & 0 \\
3 & 0.2 & $0.498 \pm 0.026^{*}$ & 35.24 \\
4 & 0.39 & $0.377 \pm 0.048^{* \#}$ & 50.98 \\
5 & 0.78 & $0.394 \pm 0.056^{* \#}$ & 48.76 \\
6 & 1.56 & $0.401 \pm 0.034^{* \#}$ & 47.85 \\
7 & 3.13 & $0.333 \pm 0.154^{* \#}$ & 56.70 \\
\hline
\end{tabular}

${ }^{*} P<0.05$ vs. the control; ${ }^{\#} P<0.05$ vs. paclitaxel only.

Table 4: Inhibitory effects of paclitaxel+hirudin complexes on HCAECs (48 h)

\begin{tabular}{|c|c|c|c|}
\hline Group no. & $\begin{array}{l}1 \quad \mu \mathrm{mol} / \mathrm{L} \\
\text { paclitaxel+differen } \\
\text { t doses of hirudin } \\
(\mathrm{mg} / \mathrm{mL})\end{array}$ & A value $(X \pm S)$ & $\begin{array}{l}\text { Inhibition } \\
(\%)\end{array}$ \\
\hline 1 (Blank) & 0 & $0.267 \pm 0.014^{\#}$ & 0 \\
\hline 2 & Paclitaxel only & $0.181 \pm 0.010^{*}$ & 32.20 \\
\hline 3 & 0.2 & $0.180 \pm 0.021^{*}$ & 32.58 \\
\hline 4 & 0.39 & $0.191 \pm 0.008^{*}$ & 28.46 \\
\hline 5 & 0.78 & $0.184 \pm 0.021^{*}$ & 30.09 \\
\hline 6 & 1.56 & $0.178 \pm 0.020^{*}$ & 33.33 \\
\hline 7 & 3.13 & $0.177 \pm 0.013^{*}$ & 33.71 \\
\hline
\end{tabular}

${ }^{*} P<0.05$ vs. the control; ${ }^{\#} P<0.05$ vs. paclitaxel only. 


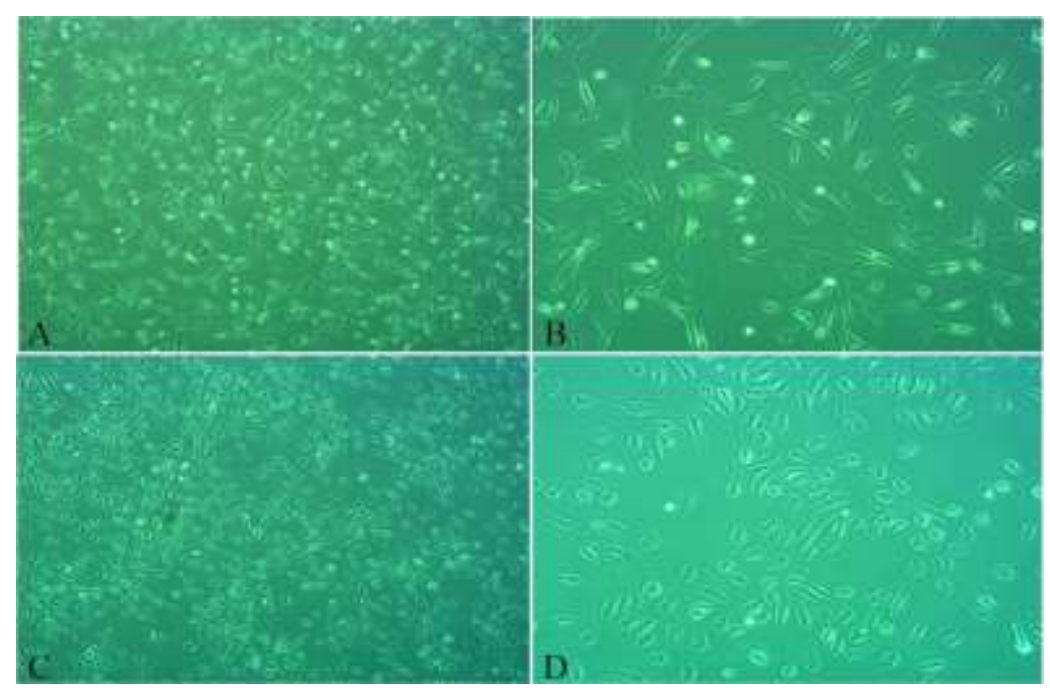

Fig. 1: Cell growth at $3 \mathrm{~d}$ under an inverted microscope. A, HCASMCs after 3-d cultivation $(40 \times)$. B, HCASMCs after 3 -d cultivation $(100 \times)$. C, HCAECs after 3-d cultivation $(40 \times)$. D, HCAECs after 3 -d cultivation $(100 \times)$.

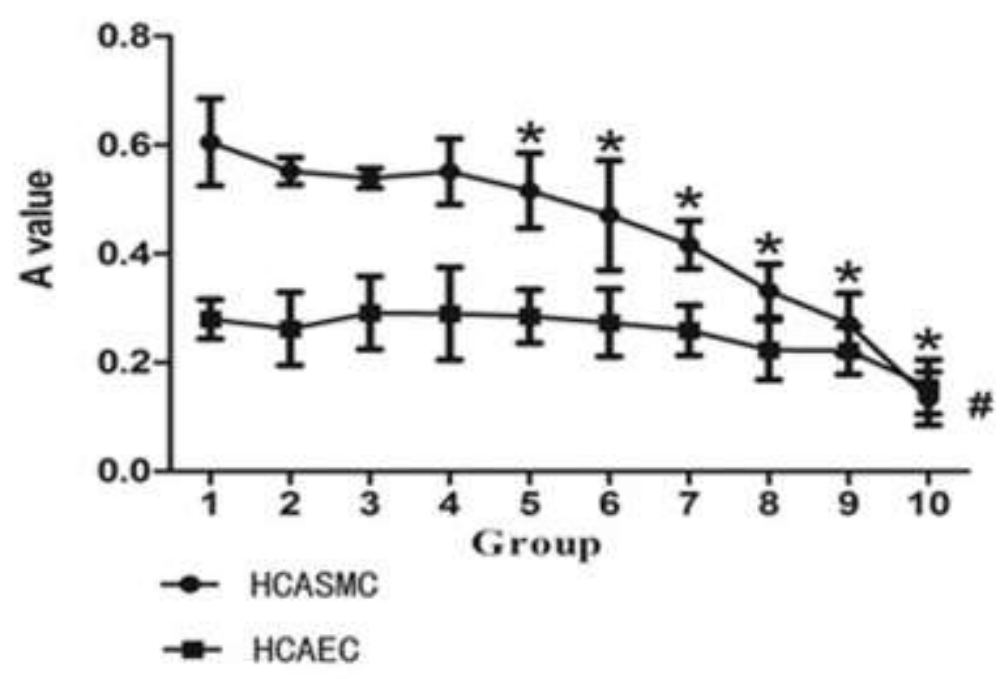

Fig. 2. The effects of different concentrations of hirudin on the growth of HCASMCs and HCAECs in vitro. Compared to the control group, hirudin obviously inhibited the growth of HCASMCs, ${ }^{*} P<0.05$. Compared to the control group, hirudin obviously inhibited the growth of HCAECs, ${ }^{\#} P<0.05$. 


$$
\text { Li and Wang }
$$

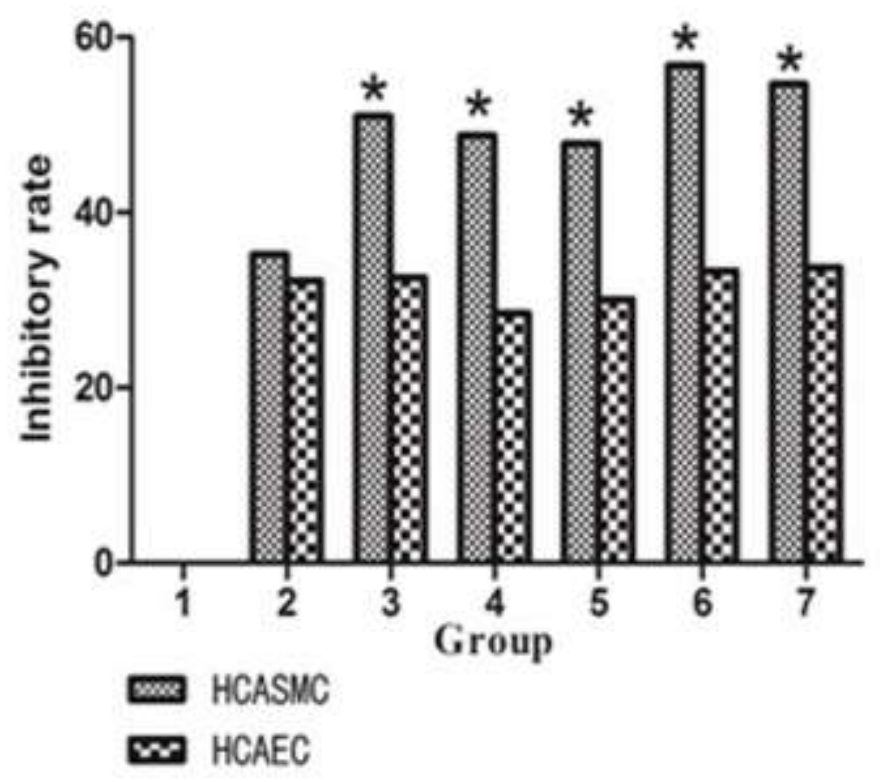

Fig. 3: Effects of paclitaxel+hirudin complexes on the growth of HCASMCs and HCAECs. *, ${ }^{\#} P<0.05$ vs. the control. 